\title{
Why women seek abortion? a qualitative study on perspectives of rural women on abortion and contraception
}

\author{
Fatima Shanthini Navis ${ }^{1}$, Nivedita Krishnamoorthy ${ }^{1 *}$, Amol Dongre ${ }^{2}$
}

\author{
${ }^{1}$ Department of OBG, ${ }^{2}$ Department of Community Medicine, Sri Manakula Vinayagar Medical College \& Hospital, \\ Puducherry, India
}

Received: 11 June 2015

Accepted: 09 July 2015

\author{
*Correspondence: \\ Dr. Nivedita Krishnamoorthy, \\ E-mail: niveog91@ yahoo.com
}

Copyright: ( $)$ the author(s), publisher and licensee Medip Academy. This is an open-access article distributed under the terms of the Creative Commons Attribution Non-Commercial License, which permits unrestricted non-commercial use, distribution, and reproduction in any medium, provided the original work is properly cited.

\section{ABSTRACT}

Background: Induced abortions have been a sensitive issue throughout the world and the reasons for which women seek abortion is diverse and depends on many social and economical factors. In India, most of the rural women are still not aware of their rights and needs regarding abortion and consider abortion as illegal. Exploring the perspectives of rural women regarding induced abortions using qualitative methodology would help us to understand their attitude towards abortion and guide us towards educating women to adopt a favorable attitude towards safe abortion and contraception. The aim of this study was to explore the rural woman's perspective of their rights and needs in relation to abortion and attitudes and beliefs regarding contraception

Methods: A descriptive qualitative study done in Sri Manakula Vinayagar Medical College \& Hospital. Nine, purposively selected rural women attending family welfare clinic for seeking termination of pregnancy after having experienced at least one or more previous abortions were subjected to in-depth interview. The participants of the study were duly counseled and informed consent was taken prior to the in-depth interview. Semi-structured guideline was used for data collection, which included background characteristics, the reasons for seeking multiple abortions and perception of their rights and needs regarding abortion and their beliefs and attitude regarding contraception. In-depth interview was carried out in Tamil and translated to English by the authors The evolving themes were summarized and manual content analysis was done.

Results: The age group of our respondents was between 22-30 years and eight respondents were multiparous whereas one respondent was a nullipara. Among the 9 respondents, 4 had a previous history of unsupervised medical abortion. The most common reason cited for repeated abortions was unwanted pregnancy due to completion of the family followed by other reasons like lack of spacing, health, financial and social reasons. In majority of the respondents both the husband and wife were involved in the decision making process but husband had the final authority. Women experienced a lot of emotional turmoil during the abortion process and feeling of guilt and pain was quite common. Most of the respondents used natural methods of contraception and many misconceptions prevailed regarding the use of contraceptives. Awareness of the legal status of abortion, the time limit and indications for legal abortions was almost negligible in these women.

Conclusion: These findings highlight the need to improve rural women's knowledge of fertility and contraception. Media and service providers should use every possible opportunity to educate women regarding the legal status of abortion and to promote contraceptive usage by creating awareness regarding safety and free availability of various contraceptives thereby clearing misconceptions regarding contraception. There is a need to educate rural women that use of a regular contraceptive method is better than undergoing repeated abortions.

Keywords: Induced abortion, Contraception, Qualitative methods, In-depth interview 


\section{INTRODUCTION}

Induced abortions have been a sensitive issue throughout the world and are a major public issue in India, due to increase in the number of unsupervised medical abortions throughout the country. More than 6 million legal abortions are performed in the country, but the actual number of abortions performed is alarmingly high and the maternal mortality due to unsafe abortions is estimated to be $8 \%$ of the maternal deaths. ${ }^{1}$

The reasons for women seeking abortion could be diverse and includes unwanted pregnancy, spacing, poverty, sex selective termination and perception that abortion is safer than contraception. Other aspects like decision making pathways and choice of service providers also depends on social and economical factors.

Most of women, whether belonging to urban or rural areas are still unaware of their rights and needs regarding abortion, time limit, eligibility etc and consider abortion as illegal. Moreover contraceptive practice is pivotal in reducing the incidence of induced abortion, but the actual couple protection rate in India is only $40.4 \%$ and this is again could be due to various wrong beliefs regarding contraception.

Exploring the above aspects like reasons for undergoing abortions, perception of their rights and needs and beliefs regarding contraception particularly, the perspectives of rural women would guide us to the reason behind ever increasing number of abortions particularly unsafe abortions. Qualitative research methodology is used in this study, as the emotional impact involved in this sensitive issue of induced abortion, would be only adequately explored by In-depth interview rather than by quantitative methods.

\section{Aim of the study}

To explore rural women's perspectives on their rights and needs in relation to abortion and attitudes and beliefs regarding contraception.

\section{METHODS}

Study design: The theoretical underpinning of the study was descriptive in nature.

Study sample and setting: Women seeking abortion service at the Family Welfare Clinic of Department of Obstetrics and Gynecology of Sri Manakula Vinayagar Medical College \& Hospital, Puducherry.

Data collection tool: Nine women, who came for abortion and had undergone at least one abortion before were interviewed by In-depth Interview technique. The sample was purposively chosen to get more insight and information for in-depth understanding and the study was carried out in a period of one year between January 2014 to January 2015
Data collection: The participants of the study were duly counseled and informed consent was taken prior to the in-depth interview. Interview was carried out by the authors of this study, ensuring adequate privacy and confidentiality as it is a personal and sensitive issue. Interview guidelines was formulated to elicit information on the following aspects like

1. Background characteristics of the respondents like age, socioeconomic class, education, occupation, community, number of pregnancies and abortions.

2. The reasons for seeking multiple abortion, decision making process and the emotional impact.

3. Perception of their rights and needs regarding abortion and the beliefs and attitude regarding contraception, which includes views regarding eligibility for abortions, legal status, sex selective abortion, time limit for abortion and beliefs regarding contraception usage.

Semi-structured guidelines were used for data collection. The in-depth interview was carried out in local language Tamil.

Data analysis: Transcription was prepared in English by the authors themselves. Conventional content analysis was done manually. The unit of the analysis was the statements. Similar statements were merged together to form the categories. The first two authors, who were trained in qualitative research methods, undertook the content analysis and the findings were reviewed by the third author. The study was approved by the Research and Ethics Committee of Sri Manakula Vinayagar Medical College and Hospital, Pondicherry.

\section{RESULTS}

\section{Background characteristics of the respondents}

The age group of the abortion seekers who responded to the in- depth interview was between 22 years - 30 years. Among the 9 respondents, 2 women were graduates, 3 were school dropouts and 4 were uneducated women. All the respondents belonged to either socio economic class of IV or V. 6 women lived in joint family and 3 in nuclear family. All but one of the respondents were Hindus. Among 9 respondents, 8 were multiparous and 1 was a nulliparous woman.

5 patients had come for their second abortion whereas 1 woman had come for her fourth and one for her fifth abortion. 2 women had come for their second abortion along with tubectomy. 1 patient has had 1 abortion prior to marriage and she had come for her second abortion along with tubectomy after completing her family. At least 4 patients gave history of undergoing unsupervised medical abortion by obtaining abortion pills from pharmacy without prescription. Another trend which was noted was that almost all the respondents had gone to private facilities to undergo abortion. 
On content analysis the following 7 themes evolved as reasons for undergoing repeated abortions. They were unwanted pregnancy due to completion of family, health reasons, lack of spacing between pregnancy, education, social reasons, financial reasons and perception that abortion was safer than using contraception. In a few respondents the themes overlapped as they had more than one reason to undergo abortion.

\section{Unwanted pregnancy due to completion of family}

Many respondents quoted unwanted pregnancy due to completion of family as the reason to undergo abortion. Even though motivated for tubectomy after completion of family, tubectomy was deferred due to various reasons in one respondent. Another respondent whose husband was persistent to have male baby, did not want to continue the present pregnancy. But as the woman felt she had completed family after having 3 female children, she had her second abortion without the knowledge of husband as he would not permit the same. She said "I convinced my husband during my $1^{\text {st }}$ termination by telling him that I will postpone pregnancy for the time being and will try for a male baby later even though I did not have such intention".

\section{Health reasons}

Health reasons like fear of complications due to obesity were cited by a nulliparous woman for undergoing abortion. Being not aware of various methods of contraception, respondents were only using abstinence and when conceived accidentally decided for abortion. This perception that MTP is safer or easier than using contraception is seen prevalent even in educated women. A 22 year old educated nulliparous lady said "I wanted to lose weight before my next pregnancy as my relations kept scaring me that my pregnancy will be complicated if I am obese. So when I conceived I decided to terminate pregnancy". Another patient decided to undergo abortion because she was feeling very weak. When she conceived her $3^{\text {rd }}$ child but again she did not use any contraception and ended up with the next pregnancy which she also terminated.

\section{Lack of spacing between pregnancy}

This was a commonly quoted reason for abortions particularly following the $1^{\text {st }}$ child. Difficulty to care for the child, not able to spend time with the husband etc were the explanations given. A 24 year old muslim woman said "When I underwent my $1^{\text {st }}$ abortion I was young and did not want to be burdened my another baby as I will not be able to spend enough time with my husband.".

\section{Financial reasons}

Financial reasons were generally quoted when a decision is made to complete the family or sometimes also in postponing the pregnancy by abortion. One respondent said "We were living in city then, and it was a very small house which will be difficult to accommodate a bigger family. My husband wanted me to undergo termination due to the living conditions.

A respondent who had 2 live children and had undergone 1 abortion said, "When I conceived my fourth child hoping for a male baby, me and my husband thought a lot about it, we decided it is good enough to bring up 2 children. We decided for abortion with family planning due to financial reasons".

A respondent who had an abortion for twin pregnancy said, "I might have considered continuing the pregnancy if it was a single baby. We cannot afford to bring up 2 children".

\section{Education}

One nulliparous respondent said that she conceived immediately following marriage and as she was pursuing studies decided for termination with the consent of the husband even though elders in the family were against it.

\section{Social reasons}

One respondent who had undergone MTP due to unwed status said, "I was 7 months pregnant but got it terminated as my in law were not in favor of our marriage as I had polio and could not earn for the family, but later they changed their mind and got us married". Another respondent who was a construction worker said that she is not exposed to any contraceptive knowledge as she is not exposed to any health worker as they lead a nomadic life in search of a job.

\section{Perception that abortion was safer than using contraception}

Respondents had a lot of misconceptions regarding contraception. Some of them said they did not have any knowledge regarding contraception but most of them had misguided ideas regarding contraception. Many respondents were aware of $\mathrm{Cu} \mathrm{T}$ but were highly misguided that it could cause perforation and death. Very few were aware of OC pills and considered that it may affect health. Barrier contraception was used by partner of some respondents but very inconsistently as they reported embarrassment to purchase condoms from shops.

\section{Decision making process}

In majority of the respondents both the husband and wife are involved in the decision making process whereas in majority of families elders are kept unaware of the process as they do not support abortion. Even though both the partners are involved in the decision making process the final decision is usually made by the husband. In a respondent who had come for her fifth abortion, husband was the major decision maker. In one respondent who husband was desirous of a male baby, the patient herself 
took the decision without the knowledge of the husband and consumed abortion pills by taking guidance from her neighbors. Despite taking individual decision, respondents are dependent on their family members either the mother or the mother in law to take care of their children during their period of absence. So they are quite comfortable taking medical abortion pills which do not require admission to the hospital. They also used false complaints like menorrhagia, to get admitted to the hospital for abortion.

\section{Emotional impact}

Respondents did experience a lot of emotional disturbances during each abortion. In a nulliparous woman the fear of not conceiving again after the MTP was present. A respondent who underwent multiple abortions said, "during each abortion I would feel guilt that I was taking away a life. Each time it used to be life and death situation as the process was painful".

Most of the respondents admitted to have profound guilt and depression during the process but when a woman was determined not to have the baby she did not have these emotions. Feeling of guilt and pain perceived during the process was negligible in case of unwanted pregnancy by the women or if pregnancy occurred before marriage.

Another observation made was that if the period of amenorrhea was more women felt more guilt. One woman said "I did not feel bad during my first MTP as I had missed periods only by 10 days I became emotional during the $2^{\text {nd }}$ abortion as I carried the pregnancy to 3 months".

Emotional disturbances due to abortions are also showed by the partners. Dilemma is present when undergoing MTP that it may be a male baby which they desired.

\section{Attitude towards contraception / sterlization}

Majority of the respondents used natural methods like abstinence, withdrawal method etc. for contraception. Lot of misconceptions prevailed regarding the use of $\mathrm{Cu} \mathrm{T}$. Many of them were not aware of OC pills and those who were aware said that they did not use them due to health reasons. Condom usage was inconsistent and men were embarrassed to purchase condoms. One respondent said that she did not use contraception as she had a low fertility potential.

Many respondents who had abortion even after completion of family cited multiple reasons for postponing sterilization. Atleast 2 respondents who were well motivated for sterilization did not undergo the procedure due to refusal by the hospital usually primary health centres using various reasons like respiratory tract infection, anemia, infection, due to baby's condition etc. or due to lack of facility in the PHC. Some respondents gave financial reasons like she had to resume work immediately after delivery. Even though for abortion they went to a private facility, respondents preferred government service for sterilization as it is free of cost. Some respondents said lack of support at home during her absence to do the household chores was the main reason to postpone sterilization. One respondent said she did not want to undergo the procedure during the winter months as she may contract "Janni" (fever with rigors).

\section{Attitude towards abortion}

Most of the respondents were not aware of the legal status of abortion as they considered it as taking away a life. There was a positive attitude towards sterilization and considered sterilization better than undergoing repeated abortions. Some considered that legal abortions are only for abnormal babies and most of them were not aware of the time limit for MTP. Almost all respondents thought that both husband and wife had to consent for MTP. Many respondents were not aware of contraceptive pills but were aware of abortion pills and some considered that sex selective abortions can be carried out even upto 6 months. Vasectomy was routinely not considered as a form of permanent contraception as they had a misconception that it can cause health problems.

\section{DISCUSSION}

The foremost reason stated by majority of women was unwanted pregnancy and the reason behind unwanted pregnancy was either non use or inconsistent use of contraception rather than contraceptive failure or due to postponement of sterilization due to various reasons even through well motivated to undergo sterilization. None of our respondents claimed to have undergone sex selective abortions but most of the respondents claimed to have known someone who had undergone sex selective abortion. The above finding is consistent with a population based study at the national level, in which unintended pregnancy, rather than the sex of the previous child underlies demand for abortion in India. ${ }^{2}$ Perception that abortion is safer than contraception or sterilization was quite common among our respondents as compared to many qualitative studies. ${ }^{3}$

The selection of private practioners as service providers by many respondents is mainly to ensure privacy and confidentiality. As many women perceived abortion as an illegal procedure in India, confidentiality is as important issue even though privacy is not a well understood concept. ${ }^{4}$

In spite of the MTP act being in force since 1972, our women have very poor knowledge regarding the details of the act. A study on abortion needs carried out in Maharashtra found that only $18 \%$ of their participants knew about the legal status of abortion and most of their participants were not aware of the time limit for abortion. ${ }^{5}$ In our study, even educated women were not aware of the legal status of abortion and the time limit until which legal abortions are permitted. 
Even though the main emphasis of this study was on reasons for abortion, an important concept evolved namely the unmet need of contraception due to various reasons. Health issues due to the use of contraception was cited by many woman as the reason for using less effective methods like periodic abstinence and withdrawal method with abortions as a backup. Reasons cited for nonuse of contraception like fear of some methods like copper $\mathrm{T}$ or OC pills, health reasons etc were similar to other studies. ${ }^{3}$

\section{CONCLUSION}

Considering the above findings, counseling women regarding contraceptive usage and clearing their doubts regarding contraception in all women in the reproductive age group and providing information through media regarding the legal status of abortion would go a long way in reducing the number of unsafe abortions. Service providers should not miss key opportunities to counsel women regarding contraception. In a larger view, the study highlights the urgent need to improve rural women's knowledge of fertility and contraception. Harmful practices like unsupervised self administration of abortion pills could be curtailed by educating women on the above aspects.

Funding: No funding sources Conflict of interest: None declared

Ethical approval: The study was approved by the Institutional Ethics Committee

\section{REFERENCES}

1. Family welfare statistics in India, Ministry of Family Welfare and Health, Govt. of India, 2011. Available from http://www.mohfw.nic.in/ Write Read Data / 18925 / 3503492088 FW Statistics 2011Revised 31 10 11.pdf.

2. Suseendran P, William S. Maternal and social factors associated with abortion in India.:A population based study. International Family planning perspectives. 2006;32(3).

3. Visaria L, Ramachandran B, Ganatra et al (2004): Abortion in India: emerging issues from the qualitative studies; Abortion Assessment Project, Centre of Health and Allied Traditions (CEHAT), Pune, at: http://www.cehat.org./aap1

4. Alka B, Hemant A. Quality of abortion care: Perspectives of clients and providers in Jharkand. Economic and political weekly. 2007, XL11 No.48, 71-80 available at: fkilp.iimb.ernet.in/pdf/Healthcare - quality / Assesment of Quality of Health Facilities \& services / Barua et al Qlty of abortion care. pdf.

5. Manish G, Sunita B, Hemalatha P. Abortion needs of women in India. A case study of rural Maharastra.. Reproductive Health Matters. 1997;5(9):77-86.

Cite this article as: Navis FS, Krishnamoorthy N, Dongre A. Why women seek abortion? a qualitative study on perspectives of rural women on abortion and contraception. Int $\mathrm{J}$ Reprod Contracept Obstet Gynecol 2015;4:1153-7. 